\title{
Exploring the Potential of Creatine Ingestion to Maintain Muscle Function during Immobilization
}

\author{
Jeremy C. Fransen ${ }^{1 *}$ and Suzanne Schneider ${ }^{2}$ \\ ${ }^{1}$ Exercise Science Program, Loyola University Chicago, Chicago, USA \\ ${ }^{2}$ Exercise Science Program, University of New Mexico, Albuquerque, USA
}

Received: 16 September, 2014; Accepted: 28 July, 2015; Published: 20 August, 2015

*Corresponding author: Jeremy C. Fransen, Assistant Professor, Marcella Niehoff School of Nursing, Exercise Science Program, Loyola University Chicago, 1032 W. Sheridan Road, BVM Hall 8th Floor, Chicago, IL 60660, Tel: +(773) 508-3263; Fax: (773) 508-3241; E-mail: jfransen@luc.edu

\begin{abstract}
Limb immobilization (casting) results in a loss of muscle mass along with decrements in muscle strength and endurance. In addition, immobilization has been shown to impair high energy phosphate catabolism in skeletal muscle. Creatine ingestion in conjunction with resistance training can significantly increase muscle force production, augment muscle size increases, and improve energy-rich phosphate catabolism in skeletal muscle. Surprisingly, there are few research studies investigating the potential of oral creatine supplementation to mitigate the muscle changes during immobilization. Early investigations found that creatine supplementation can maintain muscle size, strength, and endurance during short-term (1-2 wk) immobilization. Future research should focus on whether creatine supplementation can also prevent muscle metabolic consequences during immobilization. Creatine ingestion during short-term immobilization may help to identify the underlying mechanisms that contribute to the reported ergogenic effects.
\end{abstract}

Keywords: Casting; Muscle performance; Creatine phosphate

\section{Introduction}

The effects of muscle disuse include decreasein muscle CrossSectional Area (CSA) [1], reduced muscle specific force [2,3], alterations in muscle contractile properties [4], increased muscle protein degradation [5], change in muscle fiber type distribution from type I to type II fibers [6], neuromuscular adjustments [7], and a shift in muscle metabolic properties including loss of oxidative properties [8]. The aforementioned muscle change occurs as a result of inactivity, ageing, bed rest, spaceflight, limb suspension, or joint immobilization. Joint immobilization has been particularly useful as a model to investigate changes in skeletal muscle from disuse [5,9]. Recent evidence suggests that, Creatine (Cr) supplementation may slow the rate of muscle loss and dysfunction during cast-induced immobilization [10,11]. The goal of this article is to review the role of $\mathrm{Cr}$ in muscle energy metabolism and exercise performance, muscle function, the consequences of muscle disuse during immobilization, and to argue for the potential use of oral $\mathrm{Cr}$ supplementation to minimize the changes in muscle size and function during immobilization.

\section{Biochemistry of Creatine}

$\mathrm{Cr}$ is a nitrogenous amino acid compound with the chemical name $\alpha$-Methylguanidinoacetic Acid. Cr has a positive charge with a molecular weight of $131 \mathrm{Da}$ [12]. Cr was discovered in 1835 by the French scientist Chevreul, with the first supplementation studies beginning in the early 1900s $[13,14,15]$. The role of $\mathrm{Cr}$ in energy metabolism was clarified with the discovery of Phosphocreatine (Pcr) in 1927, followed by the Creatine Kinase (CK) reaction in 1934 [16]. CK catalyzes the reversible transfer of the $\gamma$-phosphate group of Adenosine Triphosphate (ATP) to the guanidine group of $\mathrm{Cr}$ to yield Adenosine Diphosphate (ADP), phosphocreatine (PCr) and a Proton $\left(\mathrm{H}^{+}\right)$(Figure 1). Thus, $\mathrm{Cr}$ is the substrate of $\mathrm{CK}$ to form $\mathrm{PCr}$ [12]. The high-energy phosphoryl group of PCr is transferred to ADP during exercise to maintain ATP concentrations in skeletal muscle and cross-bridge cycling.
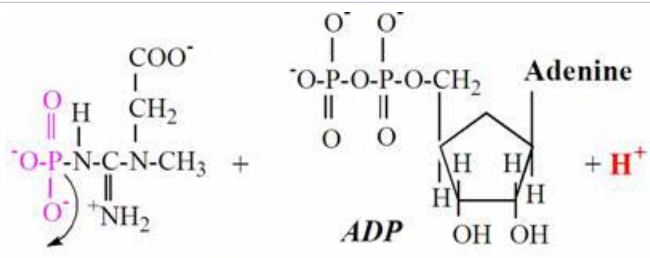

Creatine phosphate
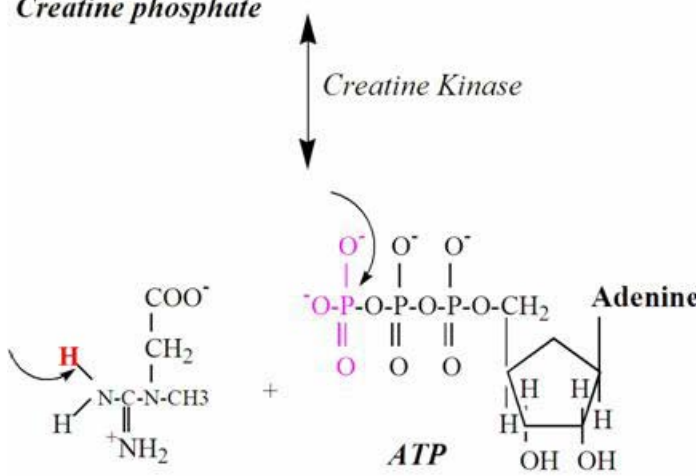

Creatine

Figure 1: The creatine kinase reaction. 
$\mathrm{Cr}$ can then be recycled or transformed to Creatinine (Crn) to be excreted in the urine [12]. During recovery from intense exercise, the large pool of $\mathrm{PCr}$ in fast-twitch skeletal muscle allows immediate regeneration of ATP (Figure 1). Due to the high cytosolic content of $\mathrm{CK}$ in skeletal muscle, the CK reaction remains at near equilibrium maintaining an almost constant ATP concentration, and thus buffers the cytosolic phosphorylation potential that is crucial for optimal cellular ATPase function [16]

The demand for $\mathrm{Cr}$ approximates $2 \mathrm{~g} \cdot \mathrm{d}^{-1}$ to replace the catabolised $\mathrm{Cr}$ that is excreted from the kidneys as creatinine (Crn) [17]. The daily requirement for $\mathrm{Cr}$ can be met through a combination of de novo biosynthesis $\left(\sim 1 \mathrm{~g} \cdot \mathrm{d}^{-1}\right)$ and intestinal absorption of dietary $\operatorname{Cr}\left(\sim 1 \mathrm{~g} \cdot \mathrm{d}^{-1}\right)$ [12]. The amino acids glycine, arginine, and methionine are involved in the endogenous synthesis of $\mathrm{Cr}$ in the liver, kidney, and pancreas. The first two steps of $\mathrm{Cr}$ biosynthesis involve the transfer of the amidino group of arginine to glycine, which is catalyzed by L-Arginine:glycine amidinotransferase (AGAT), to yield L-ornithine and guanidinoacetate. Guanidinoacetate is then methylated at the amidino group via the action of S- S-adenosyl-L-methionine:Nguanidinoacetate methyltrasferase (GAMT) to yield S-adenosyl-Lhomocysteine and $\mathrm{Cr}$ [16]. The formation of guanidinoacetate by AGAT is the rate-limiting step in $\mathrm{Cr}$ synthesis [18]. Endogenous $\mathrm{Cr}$ biosynthesis is reduced following increased dietary $\mathrm{Cr}$ ingestion [18], but returns to normal once dietary intake is reduced [19].

An omnivorous diet provides approximately $1 \mathrm{~g} \cdot \mathrm{d}^{-1} \mathrm{of} \mathrm{Cr}$ with normal plasma $\mathrm{Cr}$ levels ranging from $50-100 \mu \mathrm{mol} \cdot \mathrm{L}^{-1}[17,20]$. Typical dietary sources of $\mathrm{Cr}$ include meat, fish, and other animal products. Following ingestion, $\mathrm{Cr}$ is absorbed by the gut and enters the bloodstream where it accumulates in CK-containing tissues, predominately skeletal muscle. Greater than $90 \%$ of $\mathrm{Cr}$ enters the skeletal muscle through the binding of specific transporter proteins located in the muscle fiber membranes [12]. The main Cr transporter expressed in skeletal muscle is Creatine Transporter 1 (CRT-1) [21]. CRT-1 belongs to a super-family of neurotransmitter transporters and is mediated by $\mathrm{Na}^{+}-\mathrm{K}^{+}$ATPase mechanisms which are dependent on extracellular concentrations of $\mathrm{Na}^{+}$and $\mathrm{Cl}^{-}$[22]. The CRT-1 transport mechanism demonstrates a Michaelis-Menten constant $\left(\mathrm{K}_{\mathrm{m}}\right)$ for $\mathrm{Cr}$ in the micromolar range of 15-30 $\mu \mathrm{mol} \cdot \mathrm{L}^{-1}$, which allows for sufficient $\mathrm{Cr}$ transport into skeletal muscle [21].

An average $70 \mathrm{~kg}$ male maintains approximately $120 \mathrm{~g}$ of $\mathrm{Cr}$, of which $95 \%$ is stored in the skeletal muscle [23]. The Total Creatine (Tcr) pool in the muscle exists as both Free Creatine (Fcr) and PCr, with approximately $60 \%$ of the $\mathrm{TCr}$ as $\mathrm{PCr}$, and the remainder as $\mathrm{FCr}$ [20]. As explained earlier, $\mathrm{Cr}$ is an important source of energy for muscle contraction because of its rapid phosphorylation to form $\mathrm{PCr}$, along with the reversible rephosphorylation of ADP to form ATP via the CK reaction. Due to the limited availability of ATP and PCr in muscle, Cr supplementation may increase TCr concentrations; facilitate intramuscular $\mathrm{PCr}$ and subsequent ATP formation, thus prolonging high-intensity exercise performance [24]. Cr supplementation has also been shown to enhance myosin head cross-bridge recycling [16], buffer acidosis by consuming $\mathrm{H}^{+}$during the $\mathrm{CK}$ reaction [12], increase the rate of glycolysis through the Phosphofructokinase (PFK) reaction [25], and shorten muscle relaxation time during intermittent maximal isometric contractions [26].

\section{Muscle Changes During Immobilization}

There are substantial immediate and longer-term physiologic changes in human skeletal muscle as a consequence of disuse. Muscle fiber atrophy is one of the most studied responses to muscle disuse in humans [27]. Early research on the effects of muscle atrophy was conducted on patients that were plaster cast immobilized following limb trauma or surgery $[27,28,29,30]$. It should be noted that trauma, surgery, and pain may accelerate the atrophic response in the immobilized limb [31]. Subsequent research has used immobilization as a model for muscle disuse atrophy in healthy volunteers $[9,32]$. Additional models of disuse atrophy include limb suspension [33] and bed rest [34], which is often used to investigate muscle changes incurred during spaceflight. Although it is tempting to assign a value to the rate of muscle change or loss during disuse, research clearly shows that the type of disuse protocol and the muscle group affected determines the rate of decrement in size and function of the muscle [35].

Muscle atrophy following immobilization has been a topic of inquiry for over a century. Clinical observations of human skeletal muscle atrophy following mobilization corroborated earlier research with monkeys [36,37]. Anthropometrically measured leg volume has shown a $12 \%$ reduction following a mean of 131 days of leg immobilization [38]. Compared to disuse models of bed rest and lower limb suspension, immobilization resulted in greater atrophy (20\% decrement versus $8 \%$ ) of the quadriceps femoris muscle [39]. Veldhuizen et al. [40] investigated the effect of thigh muscle size and function following four weeks of knee immobilization. Quadriceps cross-sectional area (CSA) was calculated with Computed Tomography (CT) and showed a decrease of $21 \% \pm 7 \%(p<0.05)$. In addition, muscle biopsy from the vastus lateralis revealed a $16 \%$ decrease $(p<0.05)$ in fiber diameter. There is less data and equivocal results concerning the atrophy of the upper limbs. For example, 21 days of wrist immobilization has resulted in no significant atrophy of the forearm muscles [41], while 9 days of wrist immobilization resulted in significant atrophy $(4.1 \%$ decrease in CSA) of the forearm muscles [9]. Although there was no significant change in forearm muscle size following 21 days of wrist immobilization, there was a significant decrease in grip strength and endurance and a prolonged post-exercise $\mathrm{PCr}$ recovery period.

There are also significant alterations in neuromuscular properties that appear within the first few days of muscle disuse. Research suggests that neural factors, primarily central activation, can explain approximately $50 \%$ of the strength loss during four weeks of muscle unweighting [42]. Immobilization also has been shown to alter the functional properties of motor units [4]. For example, Clark et al. [43] evaluated the neuromuscular properties during and following 3 weeks of hand/forearm cast immobilization. Immobilization was shown to impair central activation of skeletal muscle, corticospinal excitability, and 
muscle contractile properties. These changes are surprisingly rapid and can significantly alter motor neural activity in as little as one week [44].

Deficits in strength following immobilization cannot entirely be accounted for decrease in muscle CSA and neural alterations. Metabolic factors, including changes in Inorganic Phosphate (Pi), have been shown to contribute altered muscle contractile function [45]. Pathare et al. [8] studied the effects of 7 weeks of immobilization of the ankle joint on skeletal muscle using ${ }^{31} \mathrm{P}$ MRS and muscle biopsy. Following immobilization, there was a significant decrease in plantar flexor torque and a significant increase in the Pi concentration $(p<0.001)$. Single fiber measurements demonstrated an inverse relationship between Pi concentration and relative force production. The alterations in resting Pi concentration may contribute to strength deficits during immobilization independent of decreases in CSA and neuromuscular impairments [46]. These results suggest that $\mathrm{Cr}$ supplementation may be able to play a role in maintaining muscle function during immobilization by maintaining a lower $\mathrm{Pi} / \mathrm{PCr}$ ratio and thus mitigating the decrease in muscle force production.

\section{Creatine Supplementation and Skeletal Muscle Metabolism}

Oral $\mathrm{Cr}$ supplementation at a dose of $20 \mathrm{~g} \cdot \mathrm{d}^{-1}$ for 3-5 days (loading phase) increases Total Muscle Creatine (Tcr) content, free creatine (fCr)and PCr $[17,47]$. Early work using muscle biopsies showed that $\mathrm{Cr}$ ingestion favorably improved muscle metabolism by increasing PCr availability in type II muscle fibers as well as enhancing muscle $\mathrm{PCr}$ resynthesis during recovery from intense muscle contractions resulting in fatigue resistance during short duration high-intensity exercise $[48,49,50]$. Subsequent non-invasive research on human skeletal muscle in vivo using ${ }^{31} \mathrm{P}$ MRS has shown similar muscle metabolic improvements during intermittent maximal exercise.

Yquel et al. [51] examined the effect of creatine ingestion at $20 \mathrm{~g} \cdot \mathrm{d}^{-1}$ for 6 days on muscle power, PC resynthesis, inorganic phosphate $(\mathrm{Pi})$, and $\mathrm{pH}$ during 8 repeated brief bouts of maximal dynamic plantar flexion exercise. ${ }^{31} \mathrm{P}$ MRS of the medial gastrocnemius muscle was recorded on a superconducting magnet operating at 4.7 Tesla. Following $\mathrm{Cr}$ supplementation, resting muscle $\mathrm{PCr}$ increased by $15 \%$, along with an increased rate of muscle $\mathrm{PCr}$ resynthesis, a lower $\mathrm{Pi}$ concentration, higher muscle $\mathrm{pH}$, and improved maintenance of muscle power output. In another study using ${ }^{31} \mathrm{P}$ MRS by Rico-Sanz [52], Cr supplementation (5 $\mathrm{g} \cdot \mathrm{d}^{-1} \mathrm{x}$ 11days) reduced net muscle $\mathrm{PCr}$ utilization, $\mathrm{Pi}$ accumulation, and decreases in $\mathrm{pH}$ during repeated bouts of low-intensity isometric exercise $32 \%$ of MVC) of the plantar flexors to exhaustion. These results suggest that $\mathrm{Cr}$ supplementation improves muscle metabolism during intermittent intense exercise due to a combination of enhanced muscle $\mathrm{PCr}$ stores, lowered $\mathrm{Pi}$, higher $\mathrm{pH}$, and improved $\mathrm{PCr}$ recovery kinetics.

The changes in muscle metabolism following $\mathrm{Cr}$ supplementation may be influenced by age, the muscle or muscle groups being tested, the type of muscular contraction, or the method used to assess PCr recovery kinetics. Smith et al. [53] compared the effects of $\mathrm{Cr}$ supplementation on young and middle-aged men and women during dynamic kneeextension exercise in a whole body magnet resonance system and concluded that $\mathrm{Cr}$ ingestion improved $\mathrm{PCr}$ availability and resynthesis rate in middle-aged versus younger individuals. Other research has shown no effect of $\mathrm{Cr}$ supplementation on $\mathrm{PCr}$ resynthesis rate of the gastrocnemius muscle during intermittent plantar flexor isometric contractions [26]. Subsequent research has even shown a slowing of the PCr kinetics during exercise and recovery following $\mathrm{Cr}$ supplementation [54]. It should be noted, however, that both of the aforementioned study finding shows no improvement or impaired PCr recovery kinetics reported an increase in resting $\mathrm{PCr}$ concentrations and subsequent improvements in muscle performance following $\mathrm{Cr}$ supplementation. While the exact mechanisms of muscle metabolic improvements may be debatable, the improvements in muscle strength and endurance following $\mathrm{Cr}$ supplementation remain consistent throughout the literature.

\section{Creatine Supplementation and Short-Duration High Intensity Exercise}

Cr supplementation $\left(\sim 20 \mathrm{~g} \cdot \mathrm{d}^{-1}\right)$ can increase isokinetic peak muscle torque [47,55], peak power [56], as well as improved 1 RM strength performance [57]. Cr supplementation has been shown to increase muscle power during repeated, short bouts of high-intensity exercise in young healthy females and men 30-60 years of age $[58,59]$. For example, $\mathrm{Cr}$ supplementation $(5 \times 6 \mathrm{~g} \cdot \mathrm{d}$ $\left.{ }^{1}\right)$, maintained exercise power by mitigating the decline in work output from baseline over 10 6-s bouts of intermittent high-

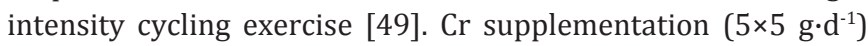
increased peak power by $20.1 \%$ (from $1061 \pm 124$ to $1325 \pm 69$ Watts) and mean power by $14.4 \%$ (from $582 \pm 58.6$ to $699 \pm 26.1$ Watts) during 3 Anaerobic Wingate Tests (AWT) with 6 min active recovery between bouts [60]. Ziegenfuss et al. [61] studied the effects of 3 days of $\mathrm{Cr}$ supplementation $\left(0.35 \mathrm{~g} \cdot \mathrm{kg}^{-1}\right.$ of fatfree mass) on 10 male and 10 female power athletes during six maximal 10s cycle sprints interspersed with $60 \mathrm{~s}$ of recovery. $\mathrm{Cr}$ supplementation resulted in statistically significant increases in body mass $(0.9 \pm 0.1 \mathrm{~kg}, p<0.03)$, total work during the first sprint $(p<0.04)$, and peak power during sprints 2 to $6(p<0.10)$.

The improvements in exercise performance from $\mathrm{Cr}$ supplementation may be due to increased skeletal muscle $\mathrm{PCr}$ which may serve as a temporal energy buffer as well as a modulator of glycolysis resulting in delayed neuromuscular fatigue. Stout et al. [62] found improvements in neuromuscular fatigue after 5 days of $\mathrm{Cr}$ loading $\left(4 \times 5 \mathrm{~g} \cdot \mathrm{d}^{-1}\right)$ in trained female athletes, with a significant $(p<0.05)$ increase in physical working capacity at the fatigue threshold. Most recently, Smith et al. [63] examined the effects of 5 days of $\mathrm{Cr}$ loading $\left(4 \times 5 \mathrm{~g} \cdot \mathrm{d}^{-1}\right)$ versus placebo (PL- 10 $\mathrm{g}$ of flavored dextrose powder) on the Electromyographic Fatigue Threshold $\left(\mathrm{EMG}_{\mathrm{FT}}\right)$ in college-aged women. Prior to and following supplementation, each subject performed a discontinuous incremental cycle ergometer test to determine their $\mathrm{EMG}_{\mathrm{FT}}$ value from the vastus lateralis muscle. $\mathrm{Cr}$ supplementation increased $\mathrm{EMG}_{\mathrm{FT}}$ from pre- to post-supplementation by $14.5 \% \pm 3.5 \%$ 
$(p=0.009)$. There was no change for the PL group $(-2.2 \pm 5.8 \%$; $p=0.732$ ). These results suggest that $\mathrm{Cr}$ may delay the onset of neuromuscular fatigue during intermittent high intensity exercise.

\section{Creatine Supplementation and Moderate to Long- Duration Exercise}

In addition to the improvements during high-intensity exercise, there is evidence that $\mathrm{Cr}$ supplementation can improve moderate to long-duration exercise performance. Preen et al. [64] examined the effect of $\mathrm{Cr}$ supplementation (20 g.d ${ }^{-1}$ for 5 days) on long-term ( $\sim 80 \mathrm{~min})$ repeated-sprint cycle exercise $(10$ sets of 5 or $6 \times 6 \mathrm{~s}$ maximal bike sprints). Total work done increased $6 \%$ (from $251.7 \pm 18.4 \mathrm{~kJ}$ to $266.9 \pm 19.3 \mathrm{~kJ} ; p<0.05$ ) following $\mathrm{Cr}$ ingestion whereas there was no change in the placebo group $(254.0 \pm 10.4 \mathrm{~kJ}$ to $252.3 \pm 9.3 \mathrm{~kJ}$; NS). Cr supplementation has been shown to improve $\mathrm{VO}_{2}$ kinetics during exercise below the Ventilatory Threshold (VT) [65]. Nelson and co-workers [66] investigated the effects of 7 days of $\mathrm{Cr}$ supplementation $\left(4 \times 5 \mathrm{~g} \cdot \mathrm{d}^{-1}\right)$ on cardiorespiratory responses to a graded exercise cycle test to exhaustion. Cr significantly increased $(p<0.05)$ total test time vs. placebo. In addition, $\mathrm{VO}_{2}$ and heart rate were significantly lower at the end of each of the first five exercise stages following $\mathrm{Cr}$ supplementation, but were unchanged after placebo. Moreover, Cr supplementation increased the VT (pre $\mathrm{Cr}=2.2 \pm 0.4 \mathrm{l} \cdot \mathrm{min}^{-1}$ or $66 \%$ of $\mathrm{VO}_{\text {2peak }}$ vs. post $\mathrm{Cr}=2.6 \pm 0.5 \mathrm{l} \cdot \mathrm{min}^{-1}$ or $78 \%$ of $\mathrm{VO}_{2 \text { peak }}$ ). In another study by Rico-Sanz and Mendez Marco (2000) [67], Cr supplementation $\left(20 \mathrm{~g} \cdot \mathrm{d}^{-1} \mathrm{x} 5 \mathrm{~d}\right)$ improved time to exhaustion from $29.9 \pm 3.8 \mathrm{~min}$ pre-Cr to $36.5 \pm 5.7 \mathrm{~min}$ post- $\mathrm{Cr}(p<0.05)$ versus no change in the placebo group [38.1 \pm 5.6 and $40.8 \pm 5.7$ min pretreatment and post-treatment, respectively (NS)].

\section{Molecular Mechanisms of Creatine Supplementa- tion for Muscle Hypertrophy}

More recently, research has focused on the effect of $\mathrm{Cr}$ supplementation on molecular pathways in skeletal muscle. Olson et al. (2006) [68] investigated the influence of $\mathrm{Cr}$ and protein supplementation on satellite cell and mononuclear number in human skeletal muscle during 16 weeks of resistance training. Using a double-blind design, 32 healthy male subjects were assigned to strength training ( 3 days per week) with either $\mathrm{Cr}$ (6-24 g; $n=9)$, protein $(20 \mathrm{~g}$; $\mathrm{n}=8)$, or placebo $(\mathrm{n}=8)$. Muscle biopsies were obtained at week $0,4,8$, and 16 of the resistance training program. Significantly greater $(p<0.05)$ enhancements in the proportion of satellite cells were observed in the $\mathrm{Cr}$ supplementation group at week 4 and week 8 . Furthermore, Cr supplementation resulted in an increase of 14$17 \%$ in Muscle Mean Fiber Area (MFA) as well as an increased number of mononuclei per fiber at week 4, 8 and 16, versus the strength training plus protein group that increased MFA by $8 \%$ in week 16 only. The results from this study demonstrate that Cr supplementation in conjunction with resistance training augments the training-induced increases in satellite cells and mononuclei in human skeletal muscle, resulting in enhanced muscle fiber growth

$\mathrm{Cr}$ can change the intracellular osmotic pressure resulting in movement of water into the cell, which can be a stimulus for protein synthesis or slowing protein breakdown [61,69]. The accumulation of $\mathrm{Cr}$ in skeletal muscle appears to stimulate transcriptional factors that regulate contractile protein synthesis, possibly as a result of increased myosin heavy chain synthesis [70]. The increase in lean body mass following $\mathrm{Cr}$ supplementation could also be mediated via anabolic signaling pathways involving increase in insulin-like growth factor I (IGF1), mRNA expression and Eukaryotic Initiation Factor-4e Binding Protein-1 (4E-BPI) [71]. Cr supplementation has been shown to upregulate mRNA content of genes and protein content of kinases involved in osmosensing and signal transduction, cytoskeleton remodeling, protein and glycogen synthesis regulation, satellite cell proliferation and differentiation, and regulation of DNA replication and repair [72].

\section{Creatine Supplementation and Immobilization}

Hespel et al. [73] studied the effects of $\mathrm{Cr}$ supplementation on muscle volume, function, and myogenic transcription factor expression during 2 weeks of leg immobilization and rehabilitation in human subjects $(\mathrm{n}=22 ; 13$ males and 9 females). Using a double-blind design, half the subjects consumed either Cr $\left(20 \mathrm{~g} \cdot \mathrm{d}^{-1}\right.$ down to $\left.5 \mathrm{~g} \cdot \mathrm{d}^{-1} ; \mathrm{n}=11\right)$ or placebo (maltodextrin; $\mathrm{n}=11$ ) for a total of 12 weeks ( 2 weeks immobilization, 10 weeks rehabilitation). Cross sectional area (CSA) of the quadriceps muscle was assessed by NMR imaging. Muscle dynamic power and isometric force of the knee-extensor muscles were assessed on an isokinetic dynamometer. In addition, muscle biopsy samples from the vastus lateralis were taken to evaluate muscle myogenic transcription factors. Measurements were taken before and after immobilization, and after weeks 3 and 10 of rehabilitation training. During rehabilitation, dynamic power and CSA recovered at a faster rate in the $\mathrm{Cr}$ supplementation group versus the placebo $(p<0.05)$. Following rehabilitation, only the $\mathrm{Cr}$ group increased Myogenic Regulatory Factor 4 (MRF4) protein expression $(p<0.05)$, which was found to be correlated with the change in mean muscle fiber diameter $(r=0.73)$. These results suggest that $\mathrm{Cr}$ can enhance muscle strength and hypertrophy during rehabilitation following disuse atrophy.

Research using the rat model has demonstrated the effectiveness of $\mathrm{Cr}$ to attenuate muscle wasting during immobilization [74]. Cr loading for 14 days (7 days prior to immobilization and together with immobilization) increased muscle $\mathrm{Cr}$ content in the lower leg muscles of the soleus by $25 \%$ and the gastrocnemius by $18 \%$. This increase in intramuscular $\mathrm{Cr}$ content is hypothesized to play a role in the mitigation of muscle loss induced by immobilization. Additionally, the researchers found an additive effect on Myosin Heavy Chain (MHC) shift to the fast phenotype with the combination of $\mathrm{Cr}$ supplementation and immobilization.

Cr supplementation has been used during arm immobilization to investigate muscle mass, strength, and endurance [10]. Using a single-blind, placebo-controlled, crossover design for 29 day, Cr was supplemented $\left(20 \mathrm{~g} \cdot \mathrm{d}^{-1}\right)$ to $\mathrm{Cr}$ naïve men $(\mathrm{n}=7 ; 18-25$ years) during 7 days of upper-limb immobilization. During immobilization, compared to placebo, $\mathrm{Cr}$ supplementation better 
maintained muscle lean tissue mass ( $\mathrm{Cr}+0.9 \%$ vs. $\mathrm{PL}-3.7 \%$ ) of the upper arm as measured with Dual-Energy X-Ray Absorptiometry (DEXA). In addition, $\mathrm{Cr}$ supplementation significantly $(p<0.05)$ maintained elbow flexor strength ( $\mathrm{Cr}-4.1 \%$ vs. PL $-21.5 \%$ ) and endurance ( $\mathrm{Cr}-9.6 \%$ vs. PL $-43 \%$ ), and elbow extensor strength $(\mathrm{Cr}-3.8 \%$ vs. $\mathrm{PL}-18 \%)$ and endurance $(\mathrm{Cr}-6.5 \%$ vs. PL $-35 \%$ ) over placebo. These results show that short-term $\mathrm{Cr}$ supplementation can slow down the muscle atrophy and strength and endurance loss during periods of immobilization.

Fransen et al. [11], investigated the effects of $\mathrm{Cr}$ supplementation on muscle performance and muscle phosphagen levels after cast-immobilization. Twenty-five active individuals $(24 \pm 4$ years, ) performed wrist flexion exercise in a 1.9 Tesla superconducting magnet before and after 1 week of cast-immobilization, while casted participants consumed either $20 \mathrm{~g}^{\text {day }^{-1}}$ of $\mathrm{Cr}$ or a placebo (PLA). An incremental protocol to fatigue and two constant load (CL1 and CL2) exercise bouts were performed. Total work was significantly reduced over time in both groups $(p=0.049)$ during the incremental exercise bout. Work production in CL1 tended ( $p=0.073$ ) to attenuate in the CR group, compared to PLA. Baseline PCr significantly decreased with casting in PLA (PRE: $26.6 \pm 6.3$ vs. POST: $22.5 \pm 5.6 \mathrm{mM} \mathrm{kg}^{-1}$ wet muscle, $p=0.003)$ with no change $(p=0.31)$ in the $\mathrm{Cr}$ group. Changes in work production were significantly correlated with changes in resting $\mathrm{PCr}$ in $\mathrm{Cr}$ group ( $\mathrm{r}=-0.63, p=0.021)$ but not PLA group ( $\mathrm{r}=-0.36, p=0.26)$. These results suggest decreases in shortterm muscle endurance following cast-immobilization may be due to alternations of $\mathrm{PCr}$ status and/or metabolism.

There are other mechanisms by which $\mathrm{Cr}$ supplementation may attenuate muscle dysfunction during periods of immobilization. For example, $\mathrm{Cr}$ supplementation has been shown to improve glucoregulation in skeletal muscle [75]. Investigation into the effect of oral $\mathrm{Cr}$ supplementation on Glucose Transporter Type 4 (GLUT4) protein content along with muscle glycogen and TCr content during immobilization and subsequent training was conducted [69]. The right leg of each participant was immobilized for two weeks after which all subjects participated in a resistance exercise program for 10 weeks. Immobilization decreased GLUT4 in the placebo group by $20 \%(p<0.05)$ with no significant change in the $\mathrm{Cr}$ group ( $+9 \%$, NS). During rehabilitation, $\mathrm{Cr}$ intake increased GLUT4 by $\sim 40 \%(P<0.05)$, whereas the placebo group normalized pre-immobilization levels. Moreover, muscle glycogen and $\mathrm{TCr}$ were higher with $\mathrm{Cr}$ supplementation following 3 weeks of retraining. These results suggest that oral $\mathrm{Cr}$ ingestion may improve glucoregulation during immobilization and during subsequent rehabilitation training.

\section{Safety of Creatine Supplementation}

In the scientific literature, $\mathrm{Cr}$ has been shown to be a safe and effective supplement. In fact, weight gain is the only documented side effect of $\mathrm{Cr}$ ingestion [76]. Despite the impressive safety record, concerns have been raised by the popular media and scientific community regarding possible adverse effects of $\mathrm{Cr}$ supplementation. There have been anecdotal reports in the popular literature that $\mathrm{Cr}$ may cause gastrointestinal upset, cause diarrhea, and promote muscle cramping and dehydration.
Schilling et al. [77] examined the long-term (0.8-4 yr) safety of $\mathrm{Cr}$ supplementation in 26 competitive athletes (18 male and 8 females, $24.7 \pm 9.2 \mathrm{yr}$ ) and found no evidence of increased incidence of muscle injury, cramps, or any other side effects. Some researchers speculated that $\mathrm{Cr}$ supplementation could result in an intracellular fluid shift that could reduce extracellular fluid compartment and impair thermoregulation. In a recent metaanalysis [78], the authors concluded that there is no evidence that supports the concept that $\mathrm{Cr}$ supplementation either hinders the body's ability to dissipate heat or negatively affect body's fluid balance. Controlled experimental trials of athletes exercising in the heat resulted in no adverse effects from $\mathrm{Cr}$ supplementation at recommended dosages of 5-20 g.day ${ }^{-1}$.

There are claims that $\mathrm{Cr}$ supplementation may promote liver damage and increase renal stress and/or impair renal function [79]. The concerns of $\mathrm{Cr}$ supplementation on renal physiology can be traced to case studies of possible renal dysfunction in individuals believed to have been supplementing $\mathrm{Cr}[80,81]$. Conclusions regarding these case studies have been criticized because two of these individuals had pre-existing kidney disease, one may have been misdiagnosed, and another was apparently taking only $25 \mathrm{mg}$ of $\mathrm{Cr}$ per serving, which makes the connection of $\mathrm{Cr}$ ingestion to renal dysfunction dubious. In each of these cases, elevations in Serum Creatinine (Crn) were initially used to diagnose renal stress. However, $\mathrm{Cr}$ is naturally degraded to Crn with the increased serum Crn levels most likely due to the initial Cr loading phase. Two case studies, $[80,81]$, involved acute renal failure in young male subjects taking $\mathrm{Cr}$ in recommended dosages with other sports supplements, it is unknown if the patients were taking anabolic steroids, which are known to increase renal stress. Contrary to these isolated case studies, $\mathrm{Cr}$ supplementation in controlled research experiments have, consistently demonstrated safety [79]. Even with this evidence it seems prudent to suggest that those with pre-existing kidney or liver disease abstain from $\mathrm{Cr}$ consumption and seek advice from a medical professional.

Studies measuring urinary Crn clearance and/or iohexol infusion techniques to assess glomerular filtration found no renal dysfunction in individuals ingesting $\mathrm{Cr}$ from 21 months to longer than 5 years $[82,83,84,85]$. In summary, there is no scientific evidence that $\mathrm{Cr}$ supplementation at recommended doses in healthy individuals can induce impairment in renal function. Likewise, there is no scientific evidence to suggest that $\mathrm{Cr}$ has any impact on liver function following short- or long-term supplementation [56]. Robinson et al. [85], reported no adverse effects on hepatic function during short-duration $\left(20 \mathrm{~g} \cdot \mathrm{d}^{-1}\right.$ for 5 days) or long-term $\left(3 \mathrm{~g} \cdot \mathrm{d}^{-1}\right.$ for 63 days) Cr supplementation.

In an effort to examine the long-term health effects of $\mathrm{Cr}$ supplementation, Kreider et al. [86], studied 98 college football players over a 21 -month period. $\mathrm{Cr}$ was administered at $15.75 \cdot \mathrm{d}^{-1}$ for 5 days and then averaged $5 \mathrm{~g} \cdot \mathrm{d}^{-1}$ for the remainder of the study. Fasting blood and 24-hr urine samples were collected at 0, 1, 1.5, $4,6,10,12,17$, and 21 months of training. Short or long-term $\mathrm{Cr}$ supplementation had no significant effect on a 54-item panel of quantitative blood and urine markers or on a 15-item panel of 
qualitative urine markers. Cr supplementation did not cause any clinically significant changes in serum metabolic markers, muscle and liver enzyme efflux, serum electrolytes, blood lipid profiles, red and white whole blood cell hematology, or quantitative and qualitative urinary markers of renal function. This study suggests Cr supplementation is safe for up to 21 months. Longer duration ( $>2$ years) studies are needed to determine continued safety.

While the hypothetical side effects of $\mathrm{Cr}$ have been hotly debated in the public media, less attention has been directed to several possible health benefits of $\mathrm{Cr}$ supplementation. For example, research suggests that $\mathrm{Cr}$ may improve blood lipid profiles. In a study conducted by Earnest et al. [87], $\mathrm{Cr}$ supplementation $\left(20 \mathrm{~g} \cdot \mathrm{d}^{-1}\right.$ for 5 days, followed by $10 \mathrm{~g} \cdot \mathrm{d}^{-1}$ for 51 days) in mildly hypertriglyceridemic and hypercholesterolemic subjects was shown to reduce plasma concentrations of total cholesterol, triacylglycerols, and very-low-density lipoprotein- $\mathrm{C}$ by $5-26 \%$, while having no effect on low-density lipoprotein-C, high-density lipoprotein-C, and Crn concentrations. There is also evidence that $\mathrm{Cr}$ supplementation may provide neuroprotection against mitochondrial dysfunction by improving neuronal cell energy metabolism thus delaying apoptosis that occurs during neurodegenerative disorders such as Alzheimer's Disease $[88,89,90]$.

\section{Conclusion}

Joint immobilization has multifaceted physiologic implications including changes in musculoskeletal morphology, neuromuscular function, muscle contractile properties, and metabolic processes. Cr supplementation in ambulatory subjects has been shown to enhance muscle glycolytic metabolism and improve local muscle and total body exercise performance. Moreover, $\mathrm{Cr}$ supplementation potentiates skeletal muscle anabolism when combined with resistance exercise training, and when used alone, mitigates muscle catabolism during periods of muscle disuse. Future research should focus on muscle metabolic consequences of immobilization combined with $\mathrm{Cr}$ supplementation. Potential benefits of $\mathrm{Cr}$ ingestion during short-term immobilization should be explored to identify the underlying mechanisms that contribute to the reported protective effects. Longer periods of immobilization and other disuse models such as bed rest and spaceflight could then be investigated to determine if $\mathrm{Cr}$ provides similar protection. In conclusion, $\mathrm{Cr}$ supplementation appears to be safe, effective, and possibly a useful countermeasure against the deleterious effects of muscle changes during joint immobilization.

\section{References}

1. Hather BM, Adams GR, Tesch PA, Dudley GA. Skeletal muscle responses to lower limb suspension in humans. J Appl Physiol. 1992; 72(4): 1493-8.

2. Yue GH, Bilodeau M, Hardy PA, Enoka RM. Task-dependent effect of limb immobilization on the fatigability of the elbow flexor muscles in humans. Exp Physiol. 1997; 82(3): 567-92.

3. Saeman MR, DeSpain K, Liu MM, Carlson BA, Song J, Baer LA, et al. Effects of exercise on soleus in severe burn and muscle disuse atrophy. J Surg Res. 2015; 198(1): 19-26. doi: 10.1016/j.jss.2015.05.038.
4. Seki K, Taniguchi Y, Narusawa M. Alterations in contractile properties of human skeletal muscle induced by joint immobilization. J Physiol. 530(3): 521-32.

5. Berg HE, Dudley GA, Häggmark T, Ohlsén H, Tesch PA. Effects of lower limb unloading on skeletal muscle mass and function in humans. J Appl Physiol. 70(4): 1882-5.

6. Desplanches D, Mayet MH, Sempore B, Flandrois R. Structural and functional responses to prolonged hind limb suspension in rat muscle. J Appl Physiol. 63(2): 558-63.

7. Duchateau J, Hainaut K. Electrical and mechanical changes in immobilized human muscle. J Appl Physiol. 62(6): 2168-73.

8. Pathare N, Walter GA, Stevens JE, Yang Z, Okerke E, Gibbs JD, et al. Changes in inorganic phosphate and force production in human skeletal muscle after cast immobilization. J Appl Physiol. 2005; 98(1): 307-14.

9. Miles MP, Clarkson PM, Bean M, Ambach K, Mulroy J, Vincent K. Muscle function at the wrist following $9 \mathrm{~d}$ of immobilization and suspension. Med Sci Sports Exerc. 1994; 26(5): 615-23.

10. Johnston AP, Burke DG, MacNeil LG, Candow DG. Effect of creatine supplementation during cast-induced immobilization on the preservation of muscle mass, strength, and endurance. J Strength Cond Res. 2009; 23(1): 116-20.

11. Fransen JC, Zuhl M, Kerksick CM, Cole N, Altobelli S, Kuethe DO, et al. Impact of Creatine on Muscle Performance and Phosphagen Stores After Immobilization. Eur J Appl Physiol. 2015.

12. Mesa JL, Ruiz JR, González-Gross MM, Gutiérrez Sáinz A, Castillo Garzón MJ. Oral creatine supplementation and skeletal muscle metabolism in physical exercise. Sports Med. 2002; 32(14): 903-44.

13. Cathcart EP. The influence of carbohydrates and fats on protein metabolism. J Physiol. 1909; 39(4): 311-30.

14. Chanutin A. The fate of creatine when administered to man. J Biol Chem. 1926; 67: 29-37.

15. Mendel LB, Rose W C. Experimental studies on creatine and creatinine: the role of the carbohydrates in creatine-creatinine metabolism. J Biol Chem. 1911; 10: 213-53.

16. Wyss M, Kaddurah-Daouk R. Creatine and Creatinine Metabolism. Physiol Rev. 2000; 80(3): 1107-213.

17. Harris RC, Söderlund K, Hultman E. Elevation of creatine in resting and exercised muscle of normal subjects by creatine supplementation. Clin Sci (Lond). 1992; 83(3): 367-74.

18. Walker JB. Creatine: biosynthesis, regulation and function. Adv Enzymol Relat Areas Mol Biol. 1979; 50: 177-242.

19. Persky AM, Brazeau GA. Clinical pharmacology of the dietary supplement creatine monohydrate. Pharmacol Rev. 2001; 53(2): 16176.

20.Williams MH, Branch JD. Creatine supplementation and exercise performance: an update. J Am Coll Nutr. 1998; 17(3): 216-34.

21. Sora I, Richman J, Santoro G, Wei H, Wang Y, Vanderah T, et al. The cloning and expression of a human creatine transporter. Biochem Biophys Res Commun. 1994; 204(1): 419-27.

22. Dai W, Vinnakota S, Qian X, Kunze DL, Sarkar HK. Molecular characterization of the human CRT-1 creatine transporter expressed in Xenopus oocytes. Arch Biochem Biophys. 1999; 361(1): 75-84.

23. Brosnan JT, da Silva RP, Brosnan ME. The metabolic burden of creatine 
synthesis. Amino Acids. 2011; 40(5): 1325-31. doi: 10.1007/s00726011-0853-y.

24. Balsom PD, Söderlund K, Sjödin B, Ekblom B. Skeletal muscle metabolism during short duration high-intensity exercise: influence of creatine supplementation. Acta Physiol Scand. 1995; 154(3): 30310.

25. Demant TW, Rhodes EC. Effects of creatine supplementation on exercise performance. Sports Med. 1999; 28(1): 49-60.

26. Vandenberghe K, Van Hecke P, Van Leemputte M, Vanstapel F, Hespel $\mathrm{P}$. Phosphocreatine resynthesis is not affected by creatine loading. Med Sci Sports Exerc. 1999; 31(2): 236-42.

27. Sargeant AJ, Davies CT, Edwards RH, Maunder C, Young A. Functional and structural changes after disuse of human muscle. Clin Sci Mol Med. 1977; 52(4): 337-42.

28. Gibson JN, Halliday D, Morrison WL, Stoward PJ, Hornsby GA, Watt PW, et al. Decrease in human quadriceps muscle protein turnover consequent upon leg immobilization. Clin Sci (Lond). 1987; 72(4): 503-9.

29. Häggmark T, Jansson E, Eriksson E. Fibre type area and metabolic potential of the thigh muscle in man after knee surgery and immobilization. Int J Sports Med. 1981; 2(1): 12-7.

30. Young A, Hughes I, Round JM, Edwards RH. The effect of knee injury on the number of muscle fibers in the human quadriceps femoris. Clin Sci (Lond). 1982; 62(2): 227-34.

31. Wolfe RR, Jahoor F, Hartl WH. Protein and amino acid metabolism after injury. Diabetes Metab Rev. 1989; 5(2): 149-64.

32. Yasuda N, Glover EI, Phillips SM, Isfort RJ, Tarnopolsky MA. Sex-based differences in skeletal muscle function and morphology with shortterm limb immobilization. J Appl Physiol. 2005; 99(3): 1085-92.

33. Dudley GA, Duvoisin MR, Adams GR, Meyer RA, Belew AH, Buchanan P. Adaptations to unilateral lower limb suspension in humans. Aviat Space Environ Med. 1992; 63(8): 678-83.

34. LeBlanc A, Gogia P, Schneider V, Krebs J, Schonfeld E, Evans H. Calf muscle area and strength changes after five weeks of horizontal bed rest. Am J Sports Med. 1988; 16(6): 624-9.

35. Clark BC. In Vivo alterations in skeletal muscle form and function after disuse atrophy. Med Sci Sports Exerc. 2009; 41(10): 1869-75. doi: 10.1249/MSS.0b013e3181a645a6.

36. Chor H, Dolkart RE. A study of 'simple disuse atrophy' in the monkey. Am J Physiol. 1936; 117: 626-630.

37. Willis CA, Caiozzo VJ, Yasukawa DL, Prietto CA, McMaster WC. Effects of immobilization of human skeletal muscle. Orthop Rev. 1982; 11: 57-64.

38. Sargeant AJ, Davies CT, Edwards RH, Maunder C, Young A. Funtional and structural changes after disuse of human muscle. Clin Sci Mol Med. 1977; 52(4): 337-42.

39. Convertino VA, Doerr DF, Mathes KL, Stein SL, Buchanan P. Changes in volume, muscle compartment, and compliance of the lower extremities in man following 30 days of exposure to simulated microgravity. Aviat Space Environ Med. 1989; 60(7): 653-8.

40. Veldhuizen JW, Verstappen FT, Vroemen JP, Kuipers H, Greep JM. Functional and morphological adaptations following four weeks of knee immobilization. Int J Sports Med. 1993; 14(5): 283-7.

41. Kitahara A, Hamaoka T, Murase N, Homma T, Kurosawa Y, Ueda C, et al. Deterioration of muscle function after 21-day forearm immobilization.
Med Sci Sports Exerc. 2003; 35(10): 1697-702.

42. Clark BC, Manini TM, Bolanowski SJ, Ploutz-Snyder LL. Adaptations in human neuromuscular function following prolonged unweighting: II. Neurological properties and motor imagery efficacy. J Appl Physiol. 2006; 101(1): 264-72.

43. Clark BC, Issac LC, Lane JL, Damron LA, Hoffman RL. Neuromuscular plasticity during and following 3 wk of human forearm cast immobilization. J Appl Physiol. 2008; 105(3): 868-78. doi: 10.1152/ japplphysiol.90530.2008.

44. Lundbye-Jensen J, Nielsen JB. Central nervous adaptations following 1 wk of wrist and hand immobilization. J Appl Physiol. 2008; 105(1): 139-51. doi: 10.1152/japplphysiol.00687.2007.

45. Cooke R, Pate E. The effects of ADP and phosphate on the contraction of muscle fibers. Biophys J. 1985; 48(5): 789-98.

46. Pathare NC, Stevens JE, Walter GA, Shah P, Jayaraman A, Tillman SM, et al. Deficit in human muscle strength with cast immobilization: contribution of inorganic phosphate. Eur J Appl Physiol. 2006; 98(1): 71-8.

47.Volek JS, Duncan ND, Mazzetti SA, Staron RS, Putukian M, Gómez $\mathrm{AL}$, et al. Performance and muscle fiber adaptations to creatine supplementation and heavy resistance training. Med Sci Sports Exerc. 1999; 31(8): 1147-56.

48. Greenhaff PL, Bodin K, Soderlund K, Hultman E. Effect of oral creatine supplementation on skeletal muscle phosphocreatine resynthesis. Am J Physiol. 1994; 266(5 Pt 1): E725-30.

49. Balsom PD, Ekblom B, Soderlund K, Sjodin B, Hultman E. Creatine supplementation and dynamic high-intensity intermittent exercise. Scandinavian Journal of Medicine and Science in Sports. 1993; 3: 14349.

50. Casey A, Constantin-Teodosiu D, Howell S, Hultman E, Greenhaff PL. Creatine ingestion favorably affects performance and muscle metabolism during maximal exercise in humans. Am J Physiol. 1996; 271(1 Pt 1): E31-7.

51.Yquel RJ, Arsac LM, Thiaudière E, Canioni P, Manier G. Effect of creatine supplementation on phosphocreatine resynthesis, inorganic phosphate accumulation and $\mathrm{pH}$ during intermittent maximal exercise. J Sports Sci. 2002; 20(5): 427-37.

52. Rico-Sanz J. Creatine reduces human muscle $\mathrm{PCr}$ and $\mathrm{pH}$ decrements and $\mathrm{Pi}$ accumulation during low-intensity exercise. J Appl Physiol. 2000; 88(4): 1181-91.

53. Smith SA, Montain SJ, Matott RP, Zientara GP, Jolesz FA, Fielding RA. Creatine supplementation and age influence muscle metabolism during exercise. J Appl Physiol (1985). 1998; 85(4): 1349-56.

54. Jones AM, Wilkerson DP, Fulford J. Influence of dietary creatine supplementation on muscle phosphocreatine kinetics during kneeextensor exercise in humans. Am J Physiol Regul Integr Comp Physiol. 2009 ; 296(4): R1078-87. doi: 10.1152/ajpregu.90896.2008.

55. Rossouw F, Kruger PE, Rossouw J. The effect of creatine monohydrate loading on maximal intermittent exercise and sport-specific strength in well trained power-lifters. Nutr Res. 2000; 20(4): 505-14.

56. Green JM, McLester JR, Smith JE, Mansfield ER. The effects of creatine supplementation on repeated upper- and lower-body Wingate performance. J Strength Cond Res. 2001; 15(1): 36-41.

57. Chrusch MJ, Chilibeck PD, Chad KE, Davison KS, Burke DG. Creatine supplementation combined with resistance training in older men. Med Sci Sports Exerc. 2001; 33(12): 2111-7. 
58. Bemben MG, Lamont HS. Creatine supplementation and exercise performance. Sports Med. 2005; 35(2): 107-25.

59. Lemon PW. Dietary creatine supplementation and exercise performance: why the inconsistent results? Can J Appl Physiol. 2002; 27(6): 663-81.

60. Havenetidis K, Bourdas D. Creatine supplementation: effects on urinary excretion and anaerobic performance. J Sports Med Phys Fitness. 2003; 43(3): 347-55

61.Ziegenfuss TN, Rogers M, Lowery L, Mullins N, Mendel R, Antonio J, et al. Effect of creatine loading on anaerobic performance and skeletal muscle volume in NCAA Division I athletes. Nutrition. 2002; 18(5): 397-402.

62. Stout J, Eckerson J, Ebersole K, Moore G, Perry S, Housh T, et al. Effect of creatine loading on neuromuscular fatigue threshold. J Appl Physiol (1985). 2000; 88(1): 109-12.

63. Smith AE, Walter AA, Herda TJ, Ryan ED, Moon JR, Cramer JT, et al Effects of creatine loading on electromyographic fatigue threshold during cycle ergometry in college-aged women. J Int Soc Sports Nutr. 2007; $4: 20$.

64. Preen D, Dawson B, Goodman C, Lawrence S, Beilby J, Ching S. Effect of creatine loading on long-term sprint exercise performance and metabolism. Med Sci Sports Exerc. 2001; 33(5): 814-21.

65. Jones AM, Carter H, Pringle JS, Campbell IT. Effect of creatine supplementation on oxygen uptake kinetics during submaximal cycle exercise. J Appl Physiol (1985). 2002; 92(6): 2571-7.

66. Nelson AG, Day R, Glickman-Weiss EL, Hegsted M, Kokkonen J, Sampson B. Creatine supplementation alters the response to a graded cycle ergometer test. Eur J Appl Physiol. 2000; 83(1): 89-94.

67. Rico-Sanz J, Mendez Marco MT. Creatine enhances oxygen uptake and performance during alternating intensity exercise. Med Sci Sports Exerc. 2000; 32(2): 379-85.

68. Olsen S, Aagaard P, Kadi F, Tufekovic G, Verney J, Olesen JL, et al Creatine supplementation augments the increase in satellite cell and myonuclei number in human skeletal muscle induced by strength training J Physiol. 2006; 573(Pt 2): 525-34.

69. Op 't Eijnde B, Ursø B, Richter EA, Greenhaff PL, Hespel P. Effect of oral creatine supplementation on human muscle GLUT4 protein content after immobilization. Diabetes. 2001; 50(1): 18-23.

70.Willoughby DS, Rosene J. Effects of oral creatine and resistance training on mysoin heavy chain expression. Med Sci Sports Exerc. 2001; 33(10): 1674-81.

71. Deldicque L, Louis M, Theisen D, Nielens H, Dehoux M, Thissen JP, et al. Increased IGF mRNA in human skeletal muscle after creatine supplementation. Med Sci Sports Exerc. 2005; 37(5): 731-6.

72. Safdar A, Yardley NJ, Snow R, Melov S, Tarnopolsky MA. Global and targeted gene expression and protein content in skeletal muscle of young men following short-term creatine monohydrate supplementation. Physiol Genomics. 2008; 32(2): 219-28.

73. Hespel P, Op't Eijnde B, Van Leemputte M, Ursø B, Greenhaff PL, Labarque $\mathrm{V}$, et al. Oral creatine supplementation facilitates the rehabilitation of disuse atrophy and alters the expression of muscle myogenic factors in humans. J Physiol. 2001; 536(Pt 2): 625-33.

74. Aoki MS, Lima WP, Miyabara EH, Gouveia CH, Moriscot AS. Deleterous effects of immobilization upon rat skeletal muscle: role of creatine supplementation. Clin Nutr. 2004; 23(5): 1176-83.

75. Ceddia RB, Sweeney G. Creatine supplementation increases glucose oxidation and AMPK phosphorylation and reduces lactate production in L6 rat skeletal muscle. J Physiol. 2004; 555(Pt 2): 409-21.

76. Dalbo VJ, Roberts MD, Stout JR, Kerksick CM. Putting to rest the myth of creatine supplementation leading to muscle cramps and dehydration. Br J Sports Med. 2008; 42(7): 567-73. doi: 10.1136/ bjsm.2007.042473.

77. Schilling BK, Stone MH, Utter A, Kearney JT, Johnson M, Coglianese R, et al. Creatine supplementation and health variables: a retrospective study. Med Sci Sports Exerc. 2001; 33(2): 183-8.

78. Lopez RM, Casa DJ, McDermott BP, Ganio MS, Armstrong LE, Maresh CM. Does Creatine Supplementation Hinder Exercise Heat Tolerance or Hydration Status? A Systematic Review with Meta-Analyses. J Athl Train. 2009; 44(2): 215-23. doi: 10.4085/1062-6050-44.2.215.

79. Yoshizumi WM, Tsourounis C. Effects of creatine supplementation on renal function. J Herb Pharmacother. 2004; 4(1): 1-7.

80. Thorsteinsdottir B, Grande JP, Garovic VD. Acute renal failure in a young weight lifter taking multiple food supplements, including creatine monohydrate. J Ren Nutr. 2006; 16(4): 341-5.

81. Taner B, Aysim 0, Abdulkadir U. The effects of the recommended dose of creatine monohydrate on kidney function. NDT Plus. 2011; 4(1): 23-4. doi: $10.1093 /$ ndtplus/sfq177.

82. Poortmans JR, Auquier H, Renaut V, Durussel A, Saugy M, Brisson GR. Effect of short-term creatine supplementation on renal responses in men. Eur J Appl Physiol Occup Physiol. 1997; 76(6): 566-7.

83. Poortmans JR, Francaux M. Long-term oral creatine supplementation does not impair renal function in healthy athletes. Med Sci Sports Exerc. 1999; 31(8): 1108-10.

84. Rasmussen C, Kreider R, Melton C, et al. Long-term creatine supplementation during football training does not affect markers of renal stress. J Strength Cond Res. 1999; 13: 431.

85. Robinson TM, Sewell DA, Casey A, Steenge G, Greenhaff PL. Dietary creatine supplementation does not affect some haematological indices, or indices of muscle damage and hepatic and renal function. Br J Sports Med. 2000; 34(4): 284-8.

86. Kreider RB, Melton C, Rasmussen CJ, Greenwood M, Lancaster S, Cantler EC, et al. Long-term creatine supplementation does not significantly affect clinical markers of health in athletes. Mol Cell Biochem. 2003; 244(1-2): 95-104.

87. Earnest CP, Almada AL, Mitchell TL. High-performance capillary electrophoresis-pure creatine monohydrate reduces blood lipids in men and women. Clin Sci (Lond). 1996; 91(1): 113-8.

88. Brewer GJ, Wallimann TW. Protective effect of the energy precursor creatine against toxicity of glutamate and beta-amyloid in rat hippocampal neurons. J Neurochem. 2000; 74(5): 1968-78.

89. Hersch SM, Gevorkian S, Marder K, Moskowitz C, Feigin A, Cox M, et al. Creatine in Huntington disease is safe, tolerable, bioavailable in brain and reduces serum 8oH2'dG. Neurology. 2006; 66(2): 250-2.

90. Matthews RT, Ferrante RJ, Klivenyi P, Yang L, Klein AM, Mueller G, et al. Creatine and cyclocreatine attenuate MPTP neurotoxicity. Exp Neurol. 1999; 157(1): 142-9. 